\title{
Patterns of Fetal Lamb Regional Cerebral Blood Flow during and after Prolonged Hypoxia
}

\author{
STEPHEN ASHWAL, "':" JOHN S. MAJCHER, NESTOR VAIN, AND LAWRENCE D. LONGO \\ Division of Perinatal Biologv, Departments of Pediatrics, /S. A., N. V.]. Phisiologv [J. S. M., L. D. L.]. and \\ Obstetrics and Gynecologv /L. D. L.J School of Medicine, Loma Linda University, Loma Linda. California, USA
}

\begin{abstract}
Summary
In an effort to determine to what extent cerebral blood flow (CBF) varies in different parts of the brain during prolonged fetal hypoxia, we measured flow to 34 regions in 12 chronically catheterized fetal lambs 130 to 140 days gestation. Control values of $\mathrm{P}_{\mathrm{O}_{2}}, \mathrm{PCO}_{2} \mathrm{pH}$, heart rate, and blood pressure were obtained, and CBF was measured by use of radioactive labeled microspheres during a control period, during $(15-, 30$, and $90-\mathrm{min})$ reduction of maternal inspired $\mathrm{O}_{2}$ concentration (fetal arterial $\mathrm{P}_{2}$ was maintained at 12 to 15 torr), and $60 \mathrm{~min}$ after returning the ewe to room air. Control blood flow to cortical, subcortical, and brainstem structures equaled 134,186 , and $254 \mathrm{ml} \cdot \mathrm{min}^{-1} \cdot 100 \mathrm{~g}^{-1}$, respectively. During hypoxia, CBF increased $92 \%$, and $60 \mathrm{~min}$ after fetal oxygenation was restored, it remained $50 \%$ above control values. We noted a similar response in regional $C B F$ to the cortex, subcortex, and brainstem during and after hypoxia. Blood flow to smaller areas within the three major regions were quite homogenous and had a similar pattern of response to hypoxia. We conclude that: (1) significant fetal regional CBF differences occurred in utero with brainstem and subcortical flows being substantially greater than flows to other regions of the brain; (2) during prolonged intrauterine hypoxia, total regional CBF increased 92\%; (3) $1 \mathrm{hr}$ after fetal oxygenation was restored, CBF still remained $50 \%$ above control values; and finally, (4) there was no significant preferential shunting of regional $\mathrm{CBF}$ during prolonged hypoxia in utero.
\end{abstract}

\section{Speculation}

In the fetal lamb during prolonged intrauterine hypoxia, total and regional cerebral blood flows increase to the same extent without evidence of preferential shunting to critical brainstem or subcortical areas. However, neuropathologic studies have indicated relative sparing of these areas during similar animal experimental or human neonatal conditions. This suggests that the pattern of hypoxic ischemic insult to the neonatal central nervous system associated with asphyxia may be due to regional metabolic derangements in cerebral tissue rather than to changes in local cerebral blood flow. Alternatively, during fetal hypotension associated with hypoxia, preferential shunting of regional blood flow might occur which could result in sparing of critical brain regions. In addition, during asphyxia, these pathologic changes may result primarily from hypotension and decreased regional cerebral blood flow.

Prolonged intrauterine hypoxia associated with fetal distress constitutes one of the most common causes of neurologic insult occurring in the neonatal period. Perinatal asphyxia causes a variety of neuropathologic changes, including severe neuronal necrosis, status marmaratus of the basal ganglia and thalamus, parasagittal cerebral neuronal necrosis, periventricular leukomalacia, and periventricular-intraventricular hemorrhage (26). Not only is the pathogenesis of such lesions poorly understood, but the underlying control mechanisms and distributions of regional cerebral blood flow during both normal conditions and perinatal asphyxia are unknown. In previous experiments in newborn monkeys, Windle (28) demonstrated that total asphyxia resulted primarily in subcortical and brainstem lesions. In contrast. Brann and Myers (3) showed in newborn monkeys that "prolonged partial asphyxia" produced by maternal hypoxia or carbon monoxide hypoxia, maternal hypotension, or umbilical cord compression primarily affected the cerebral cortex while sparing critical brainstem structures (3). These later findings are considered more applicable to human neonatal asphyxia because of the similarities observed in the distribution of neuropathologic lesions as well as in the occurrence of cerebral edema (20).

Numerous investigators have measured cerebral blood flow in the fetus and newborn animal using a variety of techniques, including measurement of cerebral venous outflow of ${ }^{1: 31} I$ (1), electromagnetic flow probes on the carotid arteries $(16,18,22)$, ${ }^{13: 3}$ xenon clearance for gray and white matter blood flow $(1,21)$, and radioisotope-labeled microspheres $(6,13,17,24)$.

Hypoxia has been noted to cause an increase in total blood flow to the fetal brain $(16,21)$, and arterial oxygen content has been considered a more important contributing factor than the partial pressure of oxygen in affecting total cerebral blood flow (11). In the hypoxic acidotic infant or fetal lamb, autoregulation appears disturbed, and hypotension has been associated with decreased cerebral blood flow $(14,15)$.

Regional cerebral blood flow has been studied to a limited extent during hypoxia. In acutely anesthetized monkeys, with the use of the $\left[^{14} \mathrm{C}\right]$ antipyrine technique, a 20 to $80^{\circ} \%$ decrease in cerebral blood flow was noted during periods of prolonged hypoxia accompanied by marked hypercarbia and acidosis (23). Recently, Lou et al. (15) used radioactive labeled microspheres to quantitate flow to four regions of the fetal lamb during variation of cerebral perfusion pressure by partial umbilical cord occlusion or by phlebotomy (15). During asphyxia, flows to all regions of the brain increased 4- to 6-fold except with the added insult of hypotension, when flows to all regions decreased uniformly.

The purpose of this study was to understand further the control mechanisms of fetal regional cerebral blood flow under both normal conditions as well as during periods of hypoxic stress. The major questions which we wished to explore were: (1) whether differences in regional cerebral blood flow to the brainstem. subcortex. and cortex occur in the fetal lamb: (2) the extent to which these flows change during and after prolonged intrauterine hypoxia: and (3) whether preferential shunting to critical areas occurs during fetal hypoxia.

\section{MATERIALS AND METHODS}

The principle of our method was to study near-term pregnant sheep and their fetuses during three different periods: control. hypoxia. and recovery. We used five separate sets of radioactive labeled microspheres to measure the blood flow to 34 separate 
regions of the central nervous system. In addition, we measured cardiac output and flow to other major organs before, during, and after hypoxia.

Twelve ewes of 120 to 140 days gestation and their fetuses were chronically catheterized. The ewe was anesthetized with $2 \mathrm{ml}$ of $0.2 \% \mathrm{HCl}$ tetracaine hydrochloride given intraspinally in addition to $400 \mathrm{mg}$ of sodium pentobarbital IV. We placed Tygon catheters ( $2.3 \mathrm{~mm}$ outside diameter) in branches of the maternal popliteal artery and uterine vein. Through a small hysterotomy incision, we extracted a fetal hindlimb, and following the injection of local anesthesia $(0.5 \%$ lidocaine $)$, we placed catheters $(1.8 \mathrm{~mm}$ outside diameter) into both a dorsal pedal artery and vein and advanced them into the descending aorta and inferior vena cava below the ductus venosus, respectively. Through a separate small incision we also extracted a fetal forelimb and after anesthetizing the skin placed two catheters, one from a radial artery into the brachiocephalic artery of the ascending aorta and one from the cephalic vein into the superior vena cava. In addition, we positioned an amniotic fluid catheter over the left chest wall. After closure in layers, the fetal and maternal catheters were exteriorized on the ewe's flank, and the ewe was left to recover.

Four to 6 days after surgery, we carried out the experiments We recorded control fetal and maternal blood pressures and heart rates. In addition, we obtained anaerobic heparinized blood samples from the fetal ascending and descending aorta, superior and inferior vena cava, maternal artery, and uterine vein; measured the $\mathrm{O}_{2}$ and $\mathrm{CO}_{2}$ tensions and $\mathrm{pH}$ using appropriate microelectrodes (Radiometer BMS 3A: London Co., Westlake, OH), and measured the hematocrit.

To determine fetal organ blood flows, we used microspheres 15 $( \pm 1) \mu \mathrm{m}$ in diameter labeled with ${ }^{57} \mathrm{Co},{ }^{51} \mathrm{Cr},{ }^{11: 3} \mathrm{Sn},{ }^{45} \mathrm{Sr}$, or ${ }^{46} \mathrm{Sc}$ (Minnesota Mining and Manufacturing Co., St. Paul, MN). These were suspended in a solution of $10 \%$ dextran and $0.05 \%$ polyoxyethylene sorbitan monooleate (Tween 80 ) to minimize aggregation and provide for even distribution. Before the experiment, we placed vials containing microspheres into an ultrasonic bath for 10 to $30 \mathrm{~min}$ for dispersion. To measure control regional cerebral flow and distribution of organ blood flow, we injected the microspheres over a 15 -sec period into the inferior $(2 / 3)$ and superior $(1 / 3)$ vena cava. During the period of injection and for $75 \mathrm{sec}$ thereafter. we withdrew blood reference samples at the rate of $4.8 \mathrm{ml} \cdot \mathrm{min}$ simultaneously from both the ascending and the descending aorta using an infusion-withdrawal pump (model 972; Harvard Apparatus Company, Inc., Millis, MA).

After placing the ewe's head in a plastic hood, we induced hypoxia by having the ewe inspire 9 to $10 \% \mathrm{O}_{2}$ and $5 \% \mathrm{CO}_{2}$ to offset the respiratory alkalosis induced by hyperventilation at a gas flow rate of $15 \cdot$ liter $\cdot \mathrm{min}^{-1}$. We sampled blood from the fetal ascending aorta every $5 \mathrm{~min}$ until the $\mathrm{O}_{2}$ tension equaled 12 to 15 torr. This was considered our zero time reference for institution of hypoxia. At 15, 30, and $90 \mathrm{~min}$ after the onset of hypoxia, we injected microspheres labeled with different radionuclides. We obtained blood for complete blood gas determinations before each microsphere injection and restored fetal blood volume with equal amounts of maternal blood. Occasionally, we administered 3 to 5 cc of sodium bicarbonate to correct the metabolic acidosis induced by hypoxia. At the end of the 90 -min hypoxic period, we removed the ewe from the hood and allowed her to breathe room air. After another $60 \mathrm{~min}$, we injected the fifth set of microspheres.

The ewe and fetus were sacrificed with $30 \mathrm{ml}$ of Euthanol solution (T61; National Laboratories Corp., Summerville, NJ). The fetus was removed, towel dried, and weighed, and the major fetal organs (heart, lungs, liver, gastrointestional tract, kidneys, adrenals, and spleen) as well as the placental cotyledons and amniotic membranes were removed, weighed, ashed, and reweighed. We dissected the fetal brain into 34 discrete regions, including the following: cortical structures-the gray and white matter of the frontal, parietal, temporal, and occipital lobes; subcortical structures thalamus, hypothalamus, caudate nucleus, hippocampus, and cerebellum: brainstem structures midbrain, pons, and medulla; as well as the cervical spinal cord. These were weighed separately and placed into plastic-covered vials. The remaining brain tissue was weighed and counted for radioactivity so that total brain blood flow could be calculated. All samples were counted for radioactivity (Auto-Gamma Scintillation Spectrometer model 5912; Packard Instrument Company, Inc., Downers Grove, IL). Specimens from the brain weighed approximately $5 \mathrm{~g}$ and contained 400 to 800 microspheres. Using a digital computer, we calculated the quantity of microspheres per organ and then converted the counts to absolute blood flows expressed as $\mathrm{ml} \cdot \mathrm{min}^{-1} \cdot 100 \mathrm{~g}^{-1}$ organ weight, $\mathrm{ml} \cdot \mathrm{min}^{-1} \cdot \mathrm{kg}$ fetus, relative flow, and percentage of cardiac output.

For each variable under consideration, we performed statistical calculations on the control measurements, the experimental measurements, and the paired differences between experimental and control values. We computed mean values, standard deviations, and standard errors of the means, and used the paired $t$ test to determine the significance of changes from control.

\section{RESULTS}

CONTROL TOTAL AND REGIONAL FETAL CEREBRAL BLOOD FLOW

Total fetal cerebral blood flow equaled 155 ( \pm 16 S.E.) $\mathrm{ml}$. $\min ^{-1} \cdot 100 \mathrm{~g}$ brain tissue ${ }^{-1}$ (Fig. 1). Flow was not uniform to all parts of the brain, however, and Figure 1 shows the hierarchy of cerebral blood flow with an increase in flow from a cephalad to a caudad direction. Thus, the mean cortical blood flow equaled 134 $( \pm 15) \mathrm{ml} \cdot \mathrm{min}^{-1} \cdot 100 \mathrm{~g}^{-1}$, the mean subcortical flow was $186( \pm 19)$ $\mathrm{ml} \cdot \mathrm{min}^{-1} \cdot 100 \mathrm{~g}^{-1}$, and the mean brainstem flow was $254( \pm 23)$ $\mathrm{ml} \cdot \mathrm{min}^{-1} \cdot 100 \mathrm{~g}^{-1}$ (Fig. 1). There was a surprising consistency of similar blood flows to various structures within the major regions, except for a slight but insignificant elevation of mean cortical gray matter flow of $139( \pm 17) \mathrm{ml} \cdot \mathrm{min}^{-1} \cdot 100 \mathrm{~g}^{-1}$ as compared to a mean white matter blood flow of $120( \pm 12) \mathrm{ml} \cdot \mathrm{min}^{-1} \cdot 100 \mathrm{~g}^{-1}$ (Fig. 1).

FETAL BLOOD GASES AND CARDIOVASCULAR RESPONSE DURING; HYPOXIA

Figure 2 depicts the changes in fetal ascending aortic $\mathrm{O}_{2}$ and $\mathrm{CO}_{2}$ tensions and $\mathrm{pH}$ during and after the 90 -min hypoxic period. During the entire hypoxic period, the ascending aortic $\mathrm{O}_{2}$ tension was maintained at 12 to 15 torr $\left(\mathrm{O}_{2}\right.$ content about $\left.5 \mathrm{ml} \cdot \mathrm{dl}^{-1}\right)$ whereas the $\mathrm{CO}$. tension remained relatively constant. Fetal $\mathrm{pH}$ decreased from a control value of $7.34( \pm 0.01)$ to $7.31( \pm 0.01)$ units at $15 \mathrm{~min}$ and to $7.24( \pm 0.02)$ at $90 \mathrm{~min}$ of hypoxia.

Figure 3 shows the slight elevation $(17 \%)$ in fetal mean arterial blood pressure during hypoxia to $54( \pm 2)$ from $46( \pm 2) \mathrm{mm} \mathrm{Hg}$ and an initial bradycardia $(15 \%)$ to $145( \pm 8)$ from $170( \pm 9)$ beats. min '. The cardiac output remained relatively constant at 551 $( \pm 38) \mathrm{ml} \cdot \mathrm{min}^{-1} \cdot \mathrm{kg}$ fetal weight ${ }^{-1}:$ however, the fraction of cardiac output to the brain doubled to $9.2( \pm 0.6)$ from $4.2( \pm 0.5) \%$.

\section{CHANGES IN REGIONAL CEREBRAL BLOOD FLOW DURING} HYPOXIA

As shown in Figure 4, after $15 \mathrm{~min}$ of hypoxia, blood flow to the brainstem increased to $541( \pm 63)$ from $254( \pm 23) \mathrm{ml} \cdot \mathrm{min}{ }^{~ '}$. $100 \mathrm{~g}^{-1}$. flow to subcortical regions increased to $348( \pm 33)$ from $186( \pm 19) \mathrm{ml} \cdot \mathrm{min}^{\prime} \cdot 100 \mathrm{~g}{ }^{1}$, and flow to the cortex increased to $257( \pm 24)$ from $134( \pm 15) \mathrm{ml} \cdot \mathrm{min}^{-1} \cdot 100 \mathrm{~g}$. Cerebral flow remained elevated at these levels during the entire hypoxic period. Even after the ewe has been returned to room air for one hr, blood flow persisted at elevated levels (Fig. 4).

At first glance, it would appear that fetal hypoxia results in preferential shunting of flow to the brainstem and subcortical regions from the cortex (Fig. 4). However, the percentage of increase in blood flow to the major brain regions remained relatively uniform. For instance, at 15 and $30 \mathrm{~min}$. flow increased $92 \%$ to all regions and at $90 \mathrm{~min}$, it increased $102 \%$. One $\mathrm{hr}$ after normal oxygen levels had been restored, but cerebral flow remained $50 \%$ above control values. Thus, there is no evidence of 


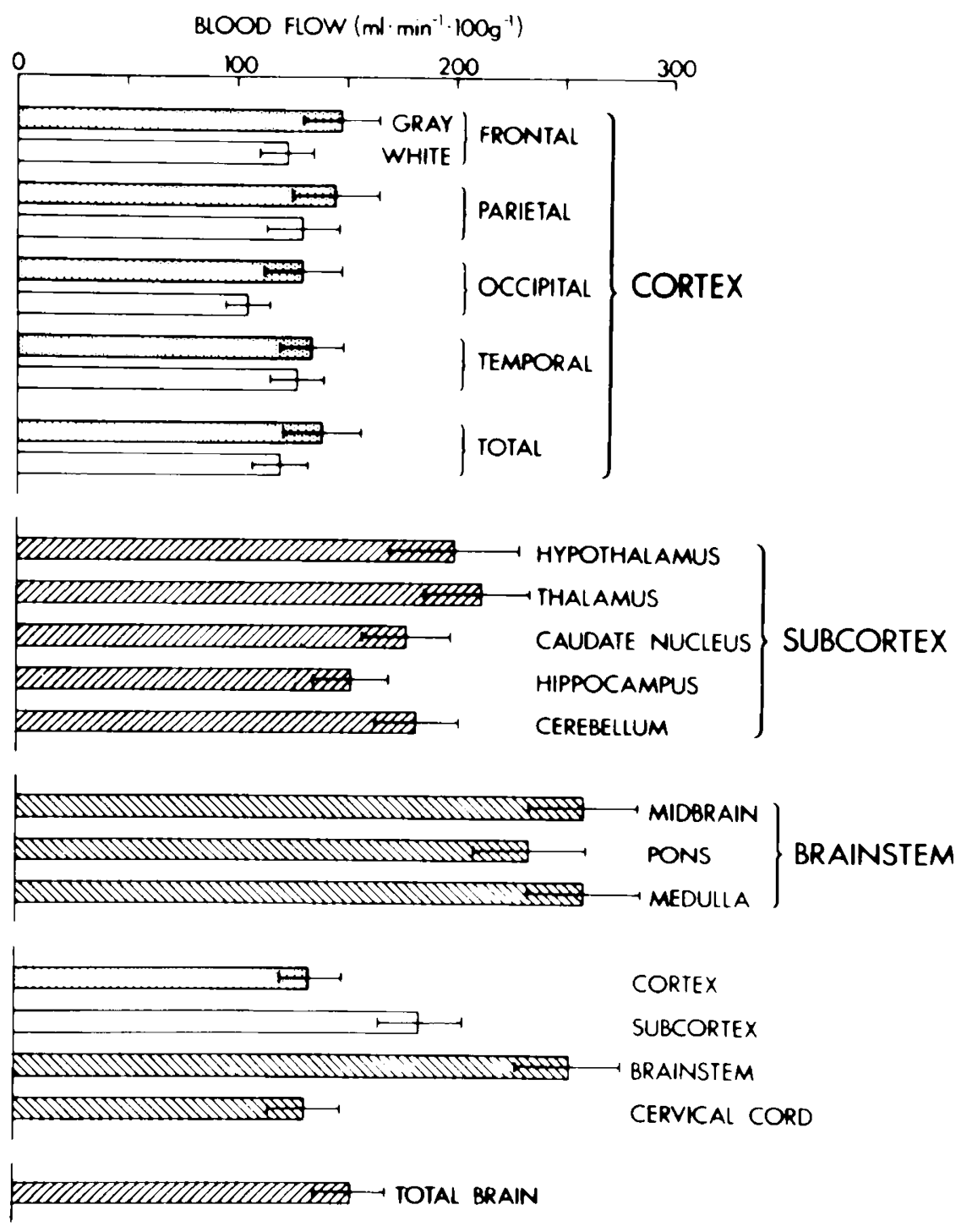

Fig. I. Control total and regional fetal cerebral blood flow $\left(\mathrm{ml} \cdot \mathrm{min}{ }^{\prime} \cdot 100 \mathrm{~g}\right.$ ') to discrete regions of the brain. Regional values are based on combined data for both right and left sides of brain. The values are means ( \pm S.E.) from 12 lambs.

preferential shunting of blood flow to certain brain regions during hypoxia.

The patterns of change in flow in the discrete brain regions within the three major areas (i.e., cortex, subcortex, and brainstem) were quite similar. For instance, in the cortex, flow changes to the frontal, parietal, temporal, and occipital areas varied only slightly. Although the gray matter tended to have higher flows than did white matter, this difference was not statistically significant. Neither were there significant differences between the blood flow to the right $[154( \pm 15)]$ and left $\left[156( \pm 17) \mathrm{ml} \cdot \mathrm{min}^{-1} \cdot 100 \mathrm{~g}^{-1}\right]$ sides of the brain or brainstem. We observed similar patterns of response in the subcortical and brainstem regions and in the cervical cord.

\section{RELATIONS BETWEEN O: CONTENT, pH, AND CEREBRAL BLOOD FLOW}

Total brain blood flow increased following decreases in oxygen content $(R=0.7111)$ (Fig. 5) or $\mathrm{O}_{2.2}$ tension $(R=0.6412)$, and the $R$ values were not significantly different. Cerebral flow similarly increased following decreased $\mathrm{pH}(R=0.5938)$ (Fig. 6).

To examine the combined effects of $\mathrm{O}_{2}, \mathrm{CO}_{2}$ and $\mathrm{pH}$ on total cerebral blood flow, we performed a multiple linear regression analysis. Cerebral flow was somewhat more highly correlated with the three variables $\mathrm{P}_{\mathrm{O}_{2}}, \mathrm{P}_{\left(\mathrm{C}_{2}\right.}$, and $\mathrm{pH}$ than with $\left[\mathrm{O}_{2}\right], \mathrm{P}_{\left({ }^{\prime}\right)_{2}}$, and $\mathrm{pH}$, but the difference between the two regressions was not statistically significant. In both instances, the regression coefficient of $\mathrm{CO}$, tension was not significantly different from zero (possibly reflecting the degree to which $\mathrm{P}_{\left({ }^{\prime}()_{2}\right.}$, was controlled during these experiments). $\mathrm{CO}_{2}$ tension was subsequently eliminated from the analysis without significant effect. The resulting empirical equation was.

$\mathrm{Q}\left(\mathrm{ml} \cdot \mathrm{min}^{-1} \cdot 100 \mathrm{~g}^{-1}\right)$

$$
=4530-9.5( \pm 1.5) \times \mathrm{Po}_{\mathrm{O}_{2}} \text { (torr) }-560( \pm 110) \times \mathrm{pH}
$$

Both regression coefficients were significant with $\mathrm{p}<10^{-5}$, and the overall regression was significant with $P<10$ 1" The multiple correlation coefficient was 0.773 .

\section{DISCUSSION}

\section{('ONTROL, REGIONAL ('EREBRAL BLOOD FLOW}

The control value of total cerebral flow of $155( \pm 16) \mathrm{ml} \cdot \mathrm{min}^{-1}$. $100 \mathrm{~g}^{-1}$ found in this study agrees with results of previous investigations using the microsphere technique $(6,13,17,24)$. Dissection of the brain into 34 specific areas allowed us to examine regional flow distribution with reasonable discrimination (Fig. I). Perhaps the most striking observation was the hierarchy of flows with a progressive increase in flow from brainstem equaling almost twice that of the cortex. There was a surprising uniformity of blood flows to various structures within these three major regions. 

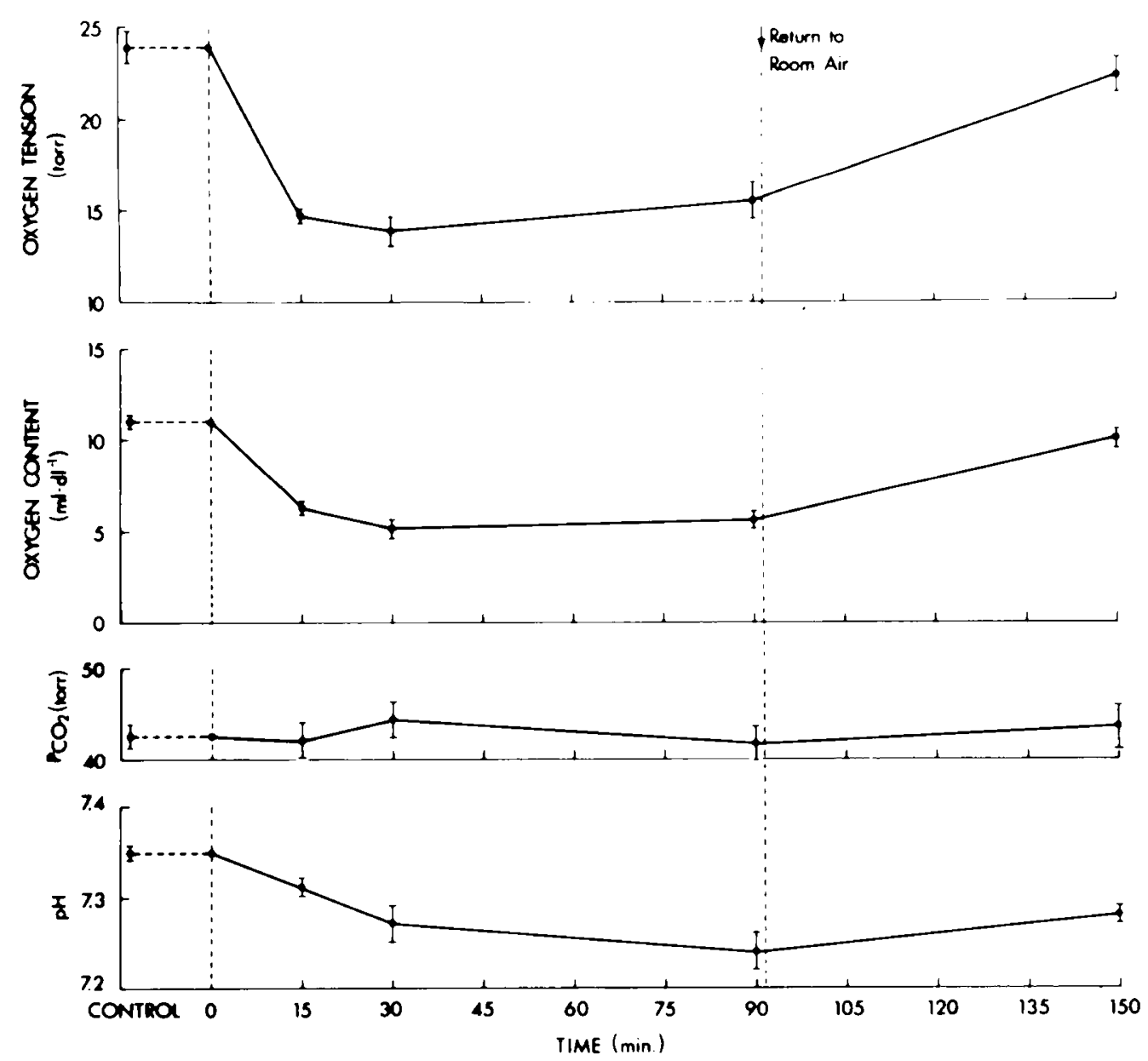

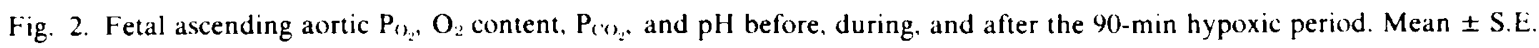

Blood flow to the cortical gray matter was slightly higher than flow to the white matter $\left[139( \pm 17)\right.$ versus $120( \pm 12) \mathrm{ml} \cdot \mathrm{min}^{-1}$. $\left.100 \mathrm{~g}^{-1}\right]$, but the difference was not statistically significant.

Our results in the fetal lamb differ considerably from those of previous studies in the newborn puppy, in which regional cerebral flow, determined by use of $\left[{ }^{14} \mathrm{C}\right]$ antipyrine $(10)$ demonstrated no significant regional differences. However, in longitudinal studies, significant regional flow differences did appear within the first few wk of life. This lack of difference in regional flows at birth was explained by the relative paucity of morphologic and functional maturation in the newborn pup because the majority of brain growth occurs during the first $13 \mathrm{wk}$ of life postnatally.

In contrast, we observed significant differences in regional cerebral flow in the fetal lamb, a fact which may reflect morphologic and functional maturation associated with the increase in brain growth near term. Although the ratio of brain to body weight of the fetal lamb is only $2 \%$ in contrast to $10 \%$ in the human fetus (8), the patterns of intrauterine brain growth in both these species are similar and suggest that the fetal lamb may serve as a reasonably good model of cerebral blood flow (19). Our studies in the fetal lamb, as well as previous studies in the newborn puppy, suggest that changes observed in regional flow relate to patterns of regional intrauterine brain growth, a circumstance which is probably a reflection of changes in local metabolism and neurophysiologic function, as well as the development of the cerebral microcirculation (10).

\section{CHANGES IN TOTAL CEREBRAL BLOOD FLOW DURING;} PROLONGED INTRAUTERINE HYPOXIA

Our finding that total brain blood flow increased 80 to $100 \%$ during the 90 -min period of intrauterine hypoxia has been noted by previous investigators using several techniques, including an electromagnetic flowmeter on the carotid artery $(16),{ }^{13: 3}$ xenon clearance (primarily measuring gray matter blood flow) (11, 21). and radioactive labeled microspheres (17). Total brain flow doubled by $15 \mathrm{~min}$ after the onset of hypoxia and persisted at this level throughout the hypoxic period. The fraction of cardiac output to the brain also doubled [ to $9.2( \pm 0.6)$ from $4.2( \pm 0.5) \%$ ] whereas the cardiac output remained constant. This suggests that the increase in cerebral blood flow resulted primarily from a change in cerebrovascular resistance because the mean arterial blood pressure increased only slightly. Although the arterial $\mathrm{pH}$ decreased to $7.24( \pm 0.02)$ at $90 \mathrm{~min}$, the linear multiple regression analysis suggests that this change in $\mathrm{pH}$ would account for about only $10 \%$ of the observed flow changes.

In contrast to these results in the fetal lamb subjected to moderate degrees of prolonged hypoxia, previous studies in the fetal monkey, lamb, and newborn puppy subjected to either prolonged partial or "total" asphyxia associated with marked hypercapnea, acidosis, and hypotension found marked decreases in total and regional cerebral blood flow, as well as significant neuropathologic changes $(3,7,11,15)$. Thus, changes in cerebral flow appear to be one of the mechanisms by which the fetus withstands prolonged intrauterine hypoxia. Apparently, it is only when additional metabolic or cardiovascular adaptive mechanisms fail that cerebral blood flow decreases, an effect perhaps associated with fetal hypotension. However, pathologic studies demonstrate cerebral edema and neuronal necrosis in the presence of significant hypotension (23). This suggests that after the hypoxic insult, cerebral edema develops and could further impair recovery by affecting the microcirculation and decreasing total cerebral flow. We currently are evaluating this possibility.

\section{CHANGES IN REGIONAL CEREBRAL BLOOD FLOW DURING HYPOXIA}

As previously discussed, we noted a hierarchy of blood flows during the control period, with flow greatest in the brainstem, less 


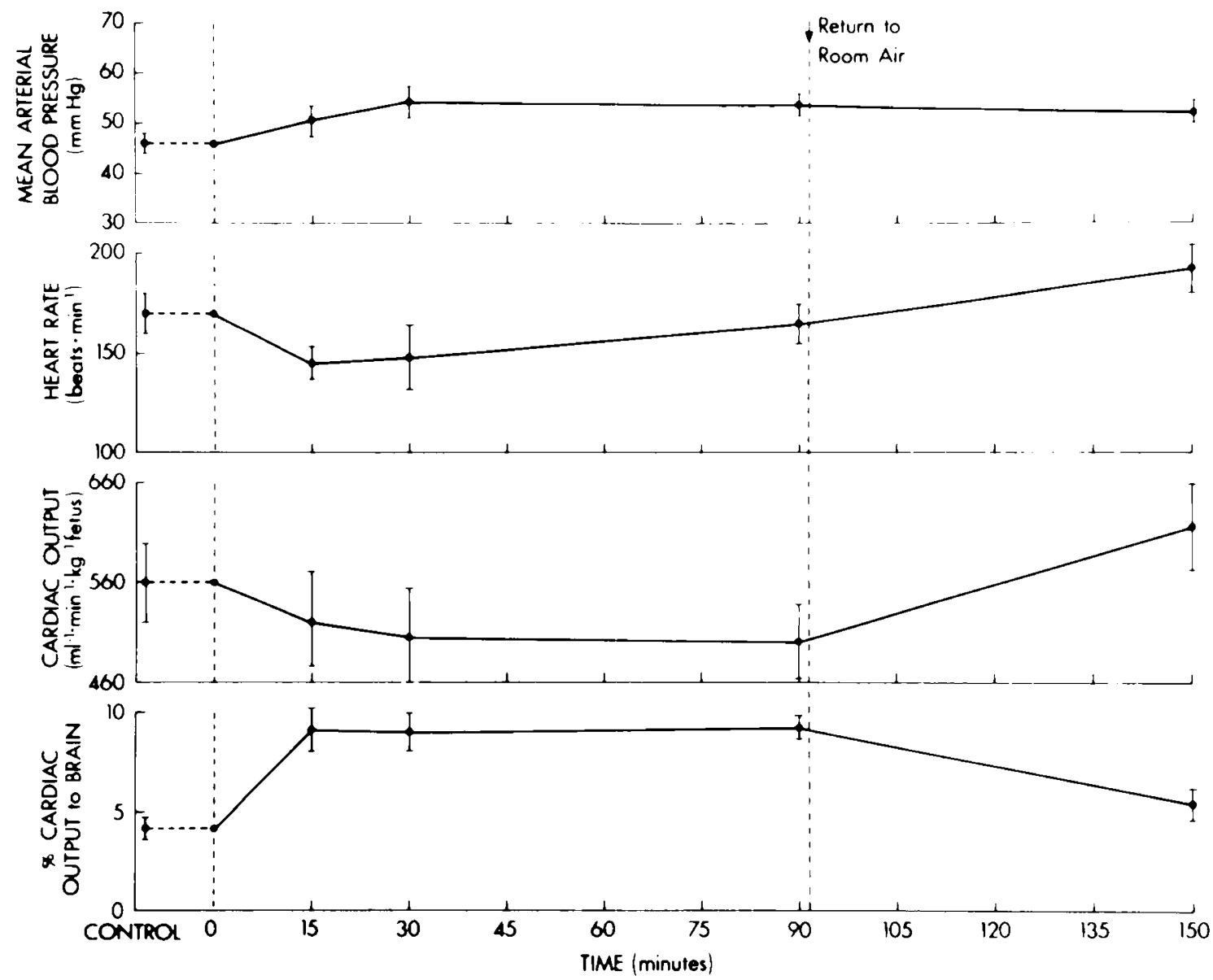

Fig. 3. Mean arterial blood pressure, heart rate, cardiac output, and percentage of cardiac output to brain before, during, and after 90 -min hypoxic period. Mean \pm S.E.

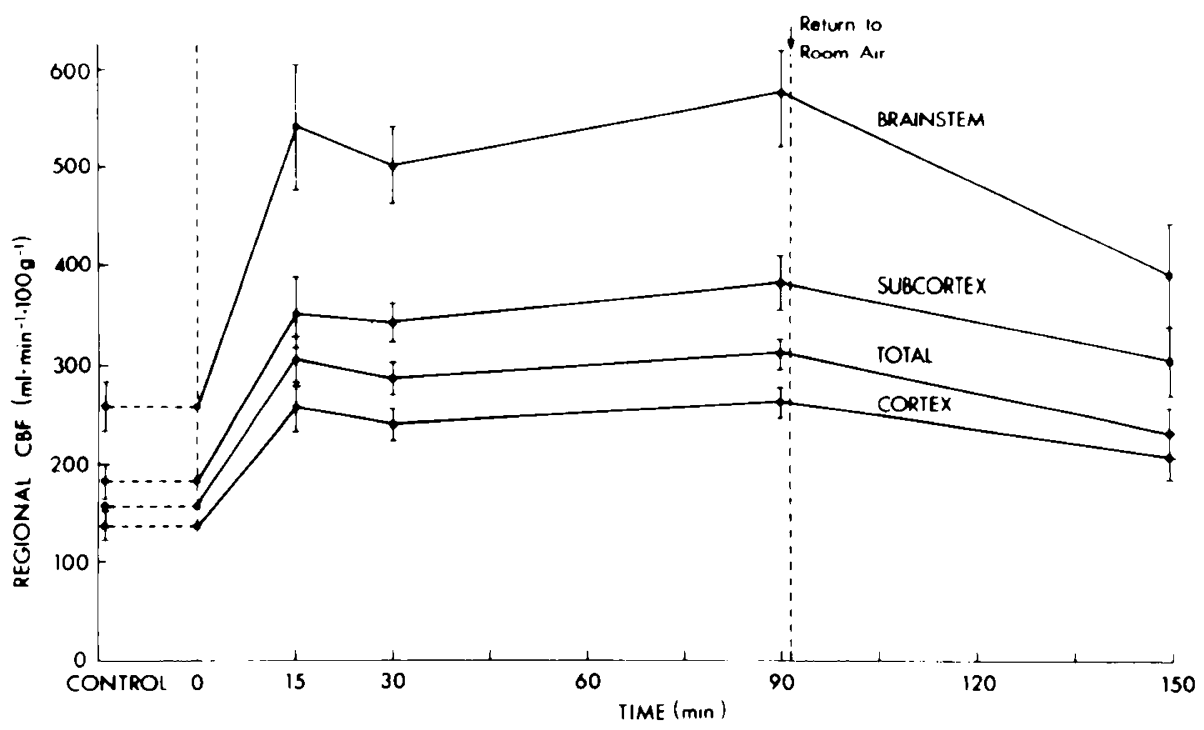

Fig. 4. Changes in total and regional fetal cerebral blood flow $\left(\mathrm{ml} \cdot \mathrm{min}^{\prime} \cdot 100 \mathrm{~g}{ }^{\prime}\right)$ to the cortex, subcortex, and brainstem during and after the 90 min hypoxic period. Mean $\pm S$.E.

in the subcortical regions, and least in the cortex (Fig. 1). During hypoxia, flow increased significantly to all regions (Fig. 4), but as noted previously, the percentage of increase to the three major regions was quite similar at 15,30 , and $90 \mathrm{~min}$, as well as $60 \mathrm{~min}$ after recovery. Thus, no preferential shunting of cerebral flow to critical brainstem or subcortical structures occurred during hypoxia, despite the greater flow to these areas under control con- ditions. This is somewhat surprising when one takes into account previous neuropathologic studies in the fetal brain subjected to "prolonged partial intrauterine asphyxia," which showed involvement of the cortex and subcortex (3) with sparing of the brainstem. This suggests that during hypoxia, blood flow within the brain might be redistributed, but this was not observed in our studies.

An additional aspect of regional flow distribution during hy- 


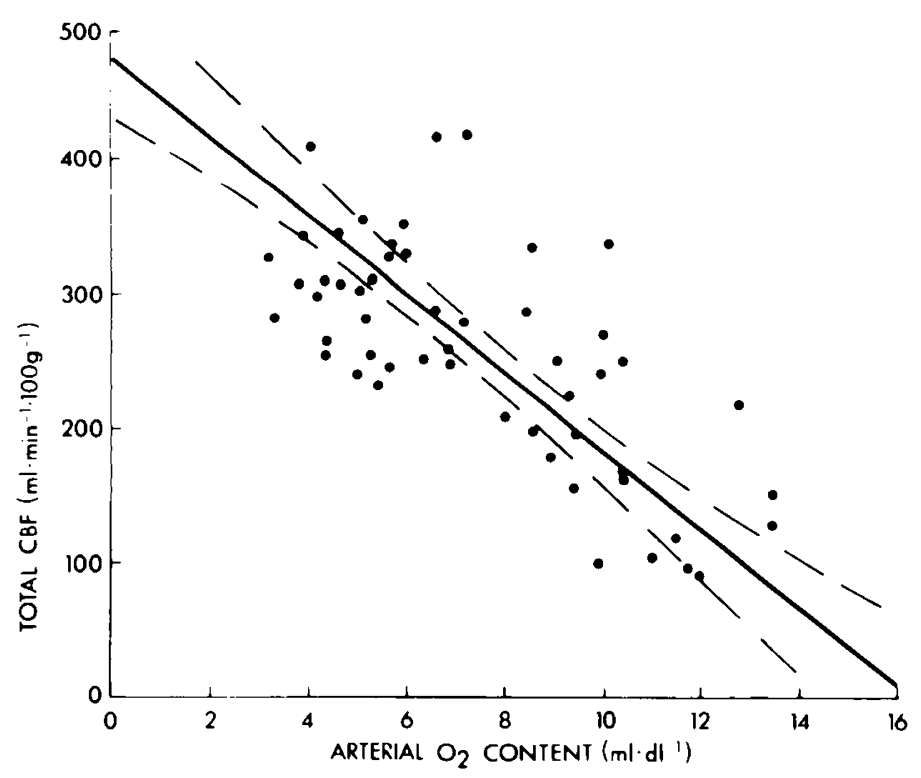

Fig. 5. Relation of fetal cerebral flow to ascending aortic $\mathrm{O}_{2}$ content $(R=0.7111)$.

poxia concerns fetal brain growth and energy metabolism. Previous studies in several species have shown that the brainstem and cerebellum are the areas of greatest brain growth during the fetal and neonatal period (2). Measurements of DNA, RNA, protein, lipid, and carbohydrate metabolism suggest that the energy requirements for these metabolically active regions are greater than for other brain areas, and these regions would be the most susceptible to an insult such as hypoxia (5). Yet this does not appear to occur. In adult cats subjected to both ischemic and hypoxic insults, changes in energy metabolism measured by $\mathrm{NADH}$ fluorescence dcmonstrated no correlation between metabolically active regions (e.g., gray matter) and the resulting metabolic changes associated with the ischemic result (27). Likewise, during hypoxia in the newborn animal, cerebral energy requirements have been shown to be lower than in adult animals, and this may be another factor accounting for the ability of the fetus to tolerate longer periods of hypoxia (25). The importance of aerobic glucose metabolism has already been demonstrated in the fetal lamb brain (9), but at the present time, no in vivo studies have examined whether regional metabolic differences occur and whether the brainstem responds differently to a metabolic insult or has potential alternative adaptive mechanisms.

\section{('EREBRAL BLOOD FLOW AFTER HYPOXIA}

Cerebral flow determined following a 60 -min recovery period when fetal heart rate, blood pressure, and blood gas values were normal remained about $50 \%$ above control values. This phenomenon was unexpected. Many metabolic disturbances have been reported in association with hypoxia. including changes in ATP. phosphocreatine, lactate, pyruvate, cyclic adenosine $3^{\prime}: 5^{\prime}$-monophosphate, and extracellular potassium concentrations $(12,25)$. The persistence of elevated cerebral blood flow is probably related to some metabolic perturbation which affects the extra and intracellular compartments, causing cerebrovascular dilatation and decreased vascular resistance. There was no significant change in blood pressure or cardiac output in these experiments to indicate any other form of compensatory cardiovascular adjustment.

DETERMINANT FAC TORS IN FETAL CEREBRAL BLOOD FLOW DURING; HYPOXIA

The multiple linear regression analysis illustrates the relation between decreases in fetal blood $\mathrm{O}_{2}$ levels and $\mathrm{pH}$ and elevation of cerebral flow. Although several previous investigators have reported that $\mathrm{O}_{2}$ content is more important than $\mathrm{O}_{2}$ tension in

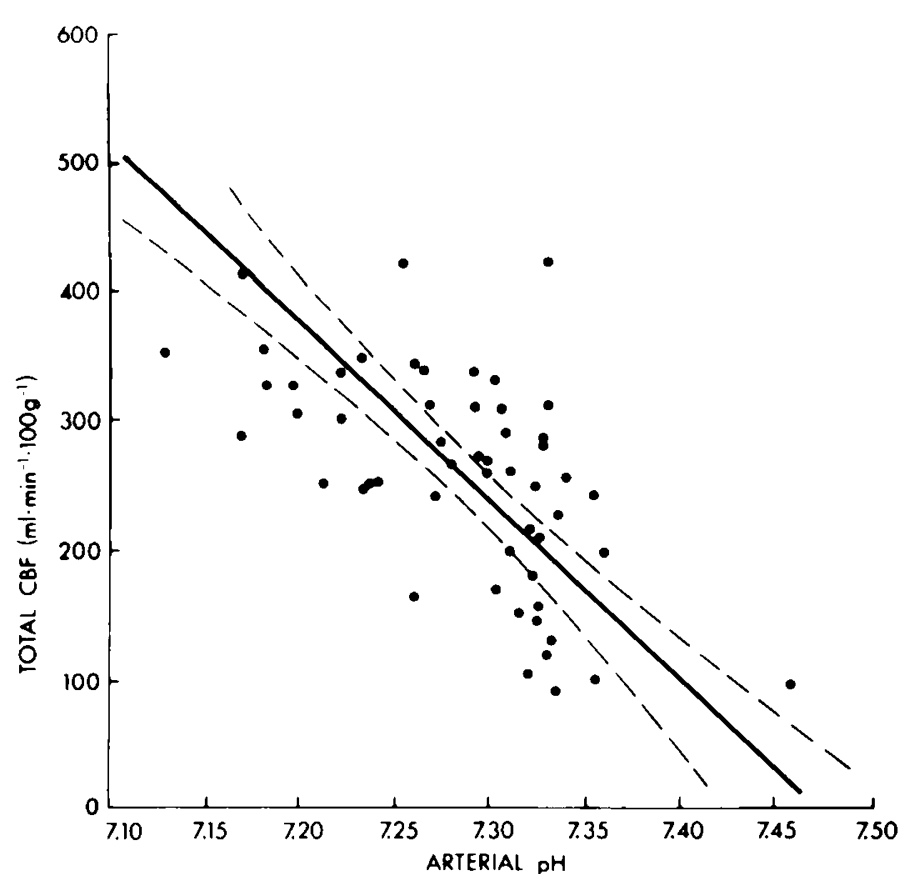

Fig. 6. Relation of total fetal cerebral flow to ascending aortic blood pH $(R=0.5938)$.

affecting cerebral flow (11), in this study the correlation coefficient obtained when $\mathrm{O}_{2}$ tension was compared to cerebral flow $(R=$ $0.6412)$ was not significantly different from that for $\mathrm{O}_{2}$ content $(R$ $=0.7111$ ).

Acidosis also is associated with increased cerebral flow $(R=$ 0.5938 ). This is known to be an important factor in controlling cerebral flow in adult as well as in newborn goats subjected to post hypoxic. lactic acid, or respiratory acidosis (4). A correlation between cerebral flow during hypoxia and acidosis in fetal lambs also has been observed in previous investigations (4), but this point is disputed (119)

In summary, many previous investigations of the response of the fetus to hypoxic stress have shown dramatic and self-protective cardiovascular, metabolic, and neuroendocrine adaptive responses. Our studies of fetal cerebral blood flow during prolonged hypoxia have noted the following: (1) significant differences in fetal regional cerebral blood flow occur in utero. Brainstem and subcortical flows are substantially greater than flows in other regions of the brain (2) during prolonged intrauterine hypoxia, total and regional cerebral flow increases between 80 and $120 \%$ and is maintained at these levels during the hypoxic period; (3) one hr after fetal oxygenation is restored, cerebral flow remains elevated 50\% above control values; (4) no significant preferential shunting of regional cerebral blood flow occurs during prolonged hypoxia in utero.

\section{REFERENCES AND NOTES}

1. Barker, J. N.: Fetal and neonatal cerebral blood flow. Am. J. Physiol., 210: 897 (1966).

2. Benjamins, J. A., and McKhann, G. M.: Neurochemistry of Development. In: R. W. Albers, R. W. Siegel. G. I. Siegel, R. Katzman. B. W. Agranoff: Basic Neurochemistry. p. 169 (Little. Brown \& Co.. Boston, 1972).

3. Brann. A. W., and Myers, R. E.: Central nervous system findings in the newborn monkey following severe in utero partial asphyxia. Neurology, 25: 327 (1975).

4. Bucciarelli, R. L.. and Eitzman, D. V.: (erebral blood flow during acute acidosis in perinatal goats. Pediatr. Res., 13: 178 (1979).

5. Davison. A. N., and Dobbing. J.: The developing brain. In: A. N. Davision, J. Dobbing: Applied Neurochemistry. p. 253 (Davis Press. Philadelphia. 1969).

6. Dunnihoo, D. R., and Quilligan. E. J.: Carotid blood flow distribution in the in utero sheep fetus. Am. J. Obstet. Gynecol., /16: 648 (1972).

7. Hernandez. M. J.. Hawkins, R. A.. Brennan. R. W.. Vannucci. R. C.. Helm. B. L.. and Bowman. G. S.: Regional cerebral blood flow during neonatal asphyxia. Fed. Proc. 38: 953 (1979).

8. Holt, A. B.. Cheek, D. B., Bellitts, D., and Hill. D. E.: Brain size and the relation 
of the primate to the non primate. In: D. G. Cheek: Fetal and Postnatal Cellular Growth. p. 23 (John Wilev \& Sons. New York. 1975).

9. Jones. M. D.. Jr., Burd. L. I. Makowski, E. L.. Meshcia, G., and Battaglia. F. C . Cerebral metabolism in sheep: a comparative study of the adult. the lamb. and the fetus. Am. J. Physiol., 229: 235 (1975).

10. Kennedy. C.. Grave, G. D.. Jehle. J. W., and Sokoloff, L.: Changes in blood flow in the component structures of the dog brain during post-natal maturation. J. Neurochem., 19: 2423 (1972).

11. Kjellmer. I., Karlsson, K.. Olsson. T., and Rosen. K. G.: Cerebral reactions during intrauterine asphyxia in the sheep. I. Circulation and oxygen consumption in the fetal brain. Pediatr. Res., 8 : $50(1974)$

12. Kogure. K.. Scheinberg. P.. Utsynomiya. Y.. Kishikawa. H., and Busto. R.: Sequential cerebral biochemical and physiological events in controlled hypoxemia. Ann. Neurol., 2: $3(1) 4$ (1977).

13. Longo. L. D., Wyatt, J. F., Hewitt, C. W., and Gilbert. R. D.: A comparison of circulatory responses to hypoxic hypoxia and carbon monoxide hypoxia in fetal blood flow and oxygenation. In: L. D. Longo, Reneau: Fetal and Newborn Cardiovascular Physiology. Vol. 2, p. 159 (Garland STPM Press. New York. 1978 ).

14. Lou. H. C.. Lassen. N. A.. and Friis-Hansen, B.: Impaired autoregulation of cerebral blood flow in the distressed newborn infant. J. Pediatr.. 44: 118 (1979).

15. Lou. H. C.. Lassen. N. A.. Tweed. W. A.. Johnson. (j.. Jones, M.. and Palahniuk. R. J.: Pressure passive cerebral blood flow and breakdown of the blood-brain barrier in experimental fetal asphyxia. Acta Paediatr. Scand. 68: 57 (1979).

16. Lucas. W., Kirschbaum, T., and Assali. N. S.: Cephalic circulation and oxygen consumption before and after birth. Am. J. Physiol.. 120: 287 (1966).

17. Makowski. E. L.. Schneider. J. M.. Tsoulos. N. G.. Colwill. J. R., Battaglia. F. C. and Meschia. G.: Cerebral blood flow, oxygen consumption and glucose utilization of fetal lambs in utero. Am. J. Obstet. Gynecol.. 114: 292 (1972).

18. Mann, L. I.: Developmental aspects and the effect of carbon dioxide tension on fetal cephalic blood flow. Exp. Neurol.. 26: 336 (1970).

19. McIntosh, G. H., Baghurst, K. I., Potter. B. J., and Hetzel, B. S.: Fetal brain development in sheep. Neuropathol. Appl. Neurobiol., 5: 103 (1979).

20. Myers. R. E.: Experimental models of perinatal brain damage: relevance to

Copyright 191980 International Pediatric Research Foundation, Inc. $0051-3998 / 80 / 1410-1104 \$ 02.00 / 0$ human pathology. In: L. Gluck: Intrauterine Asphyxia and the Developing Fetal Brain. p. 37 (Yearbook Medical Publishers. Inc.. (hicago. 1977).

21. Purves. J. J., and James. I. M.: Observations on the control of cerebral hlood flow in the sheep felus and newborn lamb. (irc. Res., 25: 651 (1964)

22. Quilligan. E. J., Hon. E. H.. Anderson. G. G.. and Hey. S-Y.: Fetal cephalic metabolism in sheep. Am. J. Obstet. Gynecol.. 101: 716 (1968).

23. Reivich. M.. Brann. A. W.. Shapiro, H. M.. and Myers, R. E.: Regional cerebral blood tlow during prolonged partial asphyxia. In: J. S. Meyer. M. Reivich. H Lechner, and $O$. Eichorn: Research on the Cerebral Circulation. Fifth International Salzburg Conference. p. 217 /Charles ( Thomas. Springfield. IL. 1972).

24. Rudolph. A. M.. and Heymann. M. A.: The circulation of the fetus in utero: methods for studying distribution of blood flow. (irc. Res.. 21: 163 (1967).

25. Vannucci. R. (.. and Duffy. T. E.: Cerebral metabolism in newborn dogs during reversible asphyxia. Ann. Neurol., 1: 528 (1977).

26. Volpe. J. J.: Observing the infant in the early hours after asphyxia. In: L. (jluck: Intrauterine Asphyxia and the Developing Fetal Brain. p. 263 (Yearbook Medical Publishers. Inc.. (hicago. 1977).

27. Welsh. F. A. and O' Conner, M. J.: Patterns of microcirculatory failure during incomplete cerebral ischemia. In: J. Cerves-Navarro: Advances in Neurology. Pathology of the Cerebrospinal Microcirculation. Vol. 20. p. 133 (Raven Press. New York, 1978).

2x. Windle. W. F.: An experimental approach to prevention or reduction of the brain damage of birth asphyxia. Dev. Med. (hild Neurol. \&: 129 (1966).

29. Presented in part at the Society for Pediatric Research Meeting. Atlanta. (ieorgia. April 4. 1979

30. The authors thank Diane McClure and Charles W. Hewitt for technical assistance

31. Requests for reprints should be addressed 10: Stephen Ashwal. M.D.. Division of Perinatal Biology. School of Medicine. Loma Linda University. Loma Linda. ( A 92350 (USA).

32. This research was supported by USPHS grant 03807

33. Received for publication October 25. 1979

34. Accepted for publication January 3.1980. 